\title{
Waste Management and Collaborative Recycling: An SDG Analysis for a Circular Economy
}

\author{
Kartikeya Durrani ${ }^{1}$
}

\begin{abstract}
The designated proposal has been a rather globally developing topic and factually alarming according to opined and definitive sources as mentioned in my final submission. Primary sources have indicated and formulated a sharp rise in the global waste produce by 70 per cent nearing 2049, along with clogging waterways, drainage passages and damaging waste-transporting infrastructure. Consolidated efforts which are necessary, certain factual implementations are also further mentioned in the submission, citing primary authorities. The collaborative recycling factor being as important as the pummeling of action which, is attributed according to how vicarious liability flows within an organization, contributing to how the most waste producing countries should take charge by coming together and joining forces. This submission also outlines and draws out how organizational-level responsibility must be implemented while accounting and moving forward with responsible waste management. It also highlights Properly disposing waste along with organic solid waste management programs which will work both ways, in the first way, it will help in supporting major waste producing countries through elemental waste reduction and recycling programs, and in the second way, help in educating the uneducated sections of the society on how to properly minimize food waste. Paving smooth budgetary transitions through recycled material and in turn, creating a circular economy which would fund itself, in a glacial but an efficient pace, thus, powering various global waste management.
\end{abstract}

Keywords: recycling, sustainable development, waste, disposal, impact, utensils, biodegradable, clay, plastic, bricks

\section{Introduction}

The primordial habits of waste disposal have clogged the opportunities for new ones to follow. The primary definition of waste management starts from the initial collection of waste (of all forms) to it's final disposal, however, through collaborative recycling, it is impediment that certain habits must be incorporated, set up and followed globally and locally in order to counter the growing surplus of non-biodegradable and hazardous waste. Consequentially, an ergonomic model which would cater to bringing in profits and service, will benefit the market for recycled goods. As a counter, during the late 1980s, land-filling and incineration has been regarded by primary waste management organizations as a major deterrent for haphazard and irresponsible disposal of waste and had set precedence for the humanity to follow ${ }^{1}$.

There are multiple problems associated with land-filling, first of them being that many materials end up as waste containing toxic substances. Through the passage of time, such toxins leach and percolate the soil including the groundwater, and this becomes hazardous for the environment for future years. Most appropriate example of toxic waste would be electronic waste. As a sub-set, discarded televisions, smart-phones, electric

\footnotetext{
${ }^{1}$ Environment Victoria, “sustainable living”, 16 th June, 2013
} 
wires and other such electronic items contain an alerting amount of hazardous substances such as Arsenics, Mercury, Cadmium, solvents, PVC, acids and lead. Another example of it would be leachate, which is the fluid shaped when squander separates in the landfill and water channels through the preliminary waste. This fluid is profoundly thick and dangerous and can contaminate the land, ground water and conduits.

The most effective of all are the ozone harming substances, this happens principally in light of the fact that when natural material, for example, nourishment scraps and green waste is placed in landfill, it is by and large compacted down and secured. This expels the oxygen and makes it separate in an anaerobic procedure. In the end, this discharges methane, an ozone depleting substance that is multiple times more powerful than carbon dioxide. The suggestions for a worldwide temperature alteration and environmental change are huge. Methane is likewise a combustible gas that can wind up hazardous whenever permitted to develop in fixation. Treating the soil with sustenance scraps and green waste in a fertilizer container kills a large number of these issues.

Aside from the monetary considerations, waste covered in a landfill separates at an exceptionally moderate rate and remains an issue which is unpredictablefor humanity.

Another challenge would be thatin spite of numerous focal points possible from building up a compelling recycling process, experience has demonstrated a few obstructions which negate the improvement of powerful recycling markets:

1. Absence of purchaser mindfulness about recycled items.

2. Absence of purchaser trust in the nature of items produced using recycled materials.

3. The social expenses and advantages are not reflected in the cost of items. Notwithstanding natural favourable circumstances, recycled items are commonly more costly than their partners produced using virgin materials.

4. The surprising expense of transporting recyclables from the point of collection to the end user.

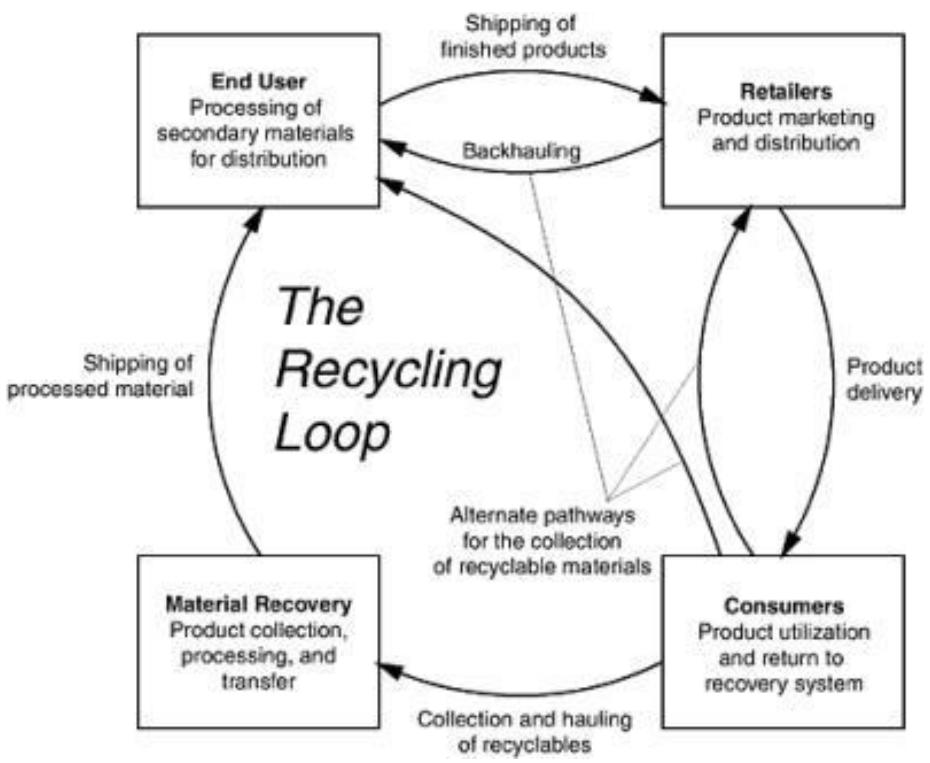


Depleting landfill space and worry about contamination from landfills and incinerators prompted a reconsideration of waste transfer rehearses during the 1980s. Reduce, Reuse, and Recycle turned into the test amid the 1990s. The common public grasped recycling in light of the fact that it provided a feeling of pride in their conviction that recycling is helpful for improving the ecological quality.

To numerous natives, the demonstration of recycling comprised of putting strong waste in compartments to be grabbed by a waste gatherer and taken to a reusing focus. Associations engaged with reusing expressed that the gathering of recyclable material is just the start of a roundabout procedure wherein recyclable assets must be sold and used to make new items and purchasers for the recycled items must be discovered.

Today, recycling faces yet another and diverse test: adequate recycling markets to monetarily support gathering programs which must be created and kept up. ${ }^{2}$

\section{Establishing a Market for Recycled Goods}

Around 1.6 million individuals worldwide are dynamic in the recycling business. Together, they handle in excess of 600 million tons of recyclables consistently. With a yearly turnover of more than $\$ 200$ billion, like the GDP of nations, for example, Portugal, Colombia and Malaysia, the area has just turned into a key driver for tomorrow's supportable advancement. About $10 \%$ of this sum is spent on new advances, innovative work that add to making high-talented employments and making recycling increasingly proficient and earth sound.

The recycling industry has turned into a vital piece for the present day society not just because of its social and financial effect, but it also assumes a crucial job for the eventual fate of our planet. The utilization of reused materials legitimately converts into less regular assets being utilized and impressively less vitality being expended when contrasted with creation forms utilizing virgin materials. ${ }^{3}$

Governments utilize a wide assortment of measures to advance recycling, such as open gathering plans for waste paper, store discount frameworks for utilized gas cylinders, reclaim programs for utilized batteries, or item models forcing a base dimension of reused content. Reusing is obviously on the ascent.

Arrangement measures to empower recycling, will just meet with restricted achievement if the business sectors for recycled items are not working admirably.

Governments are continuously requesting a more prominent extent of merchandise and materials to be reused, yet the expense of gathering these objectives is resolved to a huge degree by the commercial centres. Sadly, there is some proof that business sectors for some recyclable materials are liable to escalate disappointments and obstructions, and this can be expensive. For a certain something, wasteful markets are often subject to costunpredictability. Value instability for recyclable materials is by and large more noteworthy - and now and again multiple times more prominent - than cost vacillations for virgin materials which are close substitutes. This cost instability prompts

2 'Handbook of Solid Waste management' by Frank Kreith (eds)The McGraw-Hill Companies, Inc. 2002 under license agreement with Books24x 7

${ }^{3}$ BIR Study on the Environmental Benefits of Recycling, 2018 
vulnerability, and can demoralize this entire venture, in this manner undermining the budgetary feasibility of reusing. ${ }^{4}$

It tends to be hard for purchasers of recyclable waste to discover merchants of waste, and the other way around. These "seek" costs are normal to all business sectors, yet they may be especially high in business sectors for recyclable materials. Dissimilar to generally other assembling or administration divisions, providers are difficult to discover or gathered in one territory or even industry, since recyclable materials, paper, plastics, and so on are spread crosswise over enterprises, family units, and land territories. Foreseeing how much recyclable material will be accessible, and when, is likewise troublesome, since it is by its very nature the result of different choices. For example, the measure of scrap metal accessible from autorickshaws relies upon what number of vehicles was created and the rate of turnover of the vehicle stock. So recyclers may bring about huge costs just in distinguishing providers of recyclable material.

What's more, the nature of material being offered for reusing can differ generally, making it hard to esteem and this can result in critical expenses for purchasers and merchants in conceding to a cost. These "exchange" costs are probably going to be considerably increasingly troublesome in situations where the waste is blended (paper, plastics, and so forth) or on the other hand where the qualities of the waste are not effectively distinguishable or unmistakable.

In such cases, every shipment is one of a kind and purchasers and merchants must arrange a reasonable cost. Open specialists have frequently tried to decrease pursuit costs by making it simpler for purchasers and vendors to locate one another. An enormous number of nearby experts in OECD nations distribute arrangements of potential partners for the two purchasers and vendors of recyclable materials. In different cases, open specialists support the utilization of sites for trades - for example for development and annihilation squander in Austria and totals in the United Kingdom.

\subsection{Integrated products/materials of the market}

1. Polyester from plastic - The first consideration being deriving the fabric of polyester from any and all plastic wares, whether they are PET bottles, water bottles, plastic cutlery, plastic containers, plastic utensils, Around 49 percent of the world's attire is made of polyester and Greenpeace figures this rate to almost double by 2030, since the 'athleisure' pattern has driven a developing number of shoppers to be keen on 'stretchier', progressively safe pieces of clothing. However, polyester is certainly not a practical material choice, as it is produced using polyethylene terephthalate (PET), the most well-known kind of plastic on the planet. So, most of our garments originate from raw petroleum, while the Intergovernmental Panel on Climate Change is calling for radical activities to hold the world's temperature to a limit of $1.5{ }^{\circ} \mathrm{C}$ above premechanical dimensions.

Recycled polyester, otherwise called rPET, is obtained by liquefying and melting down existing plastic and re-turning it into new polyester fiber. While much consideration is given to rPET produced using plastic jugs and holders discarded by shoppers, as a general rule, polyethylene terephthalate can be recycled from both post-mechanical and

\footnotetext{
${ }^{4}$ OECD Policy brief, 2017
} 
post-purchaser input materials.

Collection programs must be funded within the states and the surrounding territories and finally implemented in order to carefully and efficiently distinguish between reusable plastics, un-used plastics and under-used plastics, in order to store and disseminate such collected plastics into the churning of the fabric, polyester. It is important to provide such a meticulous task being the separation of plastics so as to not allow mixing and adulteration of toxic and hazardous particles disposed along with the usable plastics, to also categorically place them along retail distribution.

These programs must supply such usable plastics, PET bottles and PLA's to retail and commercial sectors of their respective states in order to blend them into a wearable culture.

Recycled polyester gives a second life to a material that is not biodegradable and would some way or another end up in landfill or the sea. As per NGO Ocean Conservancy, 8 million metric huge amounts of plastics enter the sea consistently, over the evaluated 150 million metric tons that at present course in marine situations. In the event that we keep this pace, by 2050 there will be more plastic in the sea than fish. Plastic has been found in 60 percent everything being equal and 100 percent of all ocean turtle species since they botch plastic for sustenance, additionally as indicated by Ocean Conservancy.

To set a precedent, five soft drink containers yield enough fiber for one additional huge T-shirt.

2. Ash to Bricks and mortar - Fly ash bricks (FAB's) are derived from bond shading while the shade of Clay bricks contrasts from consumed red to light dark colored relying upon the kind of mud utilized for production of the blocks.

Clay is commonly entangled during the development of coal. At the point when coal is burnt, the incombustible clay particles are abandoned as cinder. In mesh boilers, incombustible fiery debris agglomerates as soot through delayed private time. These days, pummelled coal innovation is favoured because of its improved vitality productivity. For this situation, the ground dirt escapes alongside pipe gases, settling as cinder in pack channels or electro static precipitators (ESPs). This offers the name 'fly $\operatorname{ash}^{\prime} 5$

- FAB's thrown in molds subsequently are dependably of uniform shape. Clay bricks are carefully assembled causing slight changes in their shape and size.

- FAB's have an exceptionally smooth completion and texture consequently mortar isn't required on the blocks to make a smooth surface. Clay bricks and mud blocks require putting.

- Mud blocks and Clay bricks are more permeable and porous than FABs.

- FAB's are lighter in weight and less expensive than Clay blocks. FAB's are made of waste materials which originate from the ignition of coal in warm power plants. Dirt blocks are made of mud which is gathered from rich land or the top soil. This is the prime reason that makes FAB's ideal than Clay blocks.

- FAB's are of concrete shading while the shade of Clay bricks varies from consumed

${ }^{5}$ Fly ash for Sustainable Development authored by Dr $\mathrm{N}$ Bhanumathidas and $\mathrm{N}$ Kalidas; Ark Communications 2002 
red to light dark coloured relying upon the sort of earth utilized for assembling of the blocks.

- FAB's are made of waste materials which originate from the ignition of coal in warm power plants. Clay brick are made of mud which is gathered from prolific land or the top soil. This is the prime reason that makes FAB's are more ideal than Clay bricks. ${ }^{6}$

3. Bio-degradable plastics and Bio-plastics -As with such huge numbers of mechanical advances, plastics carry gigantic advantages to society as well as grave dangers whenever abused. From one viewpoint they enable us to make products that would some way or another be difficult to manufacture financially, merchandise that we depend on in regular day to day existence. Then again, plastics have two incredible ecological debilitations.

To begin with, by far, most are produced using non-sustainable non-renewable energy sources, oil and petroleum gas. Besides, their attractive ideals of solidarity, dormancy to synthetics, microorganisms and light likewise make them hard to discard in an ecoaccommodating way. With normal polymers, explicit compounds have created more than billions of years to help fast debasement; for the greater part of the plastics created in the course of the most recent 80 years, no such chemicals exist.

Biodegradable plastics are those that can be debased and then biodegrade by microbial and bacterial activity to create regular finished results, similar to water and carbon dioxide, in a sensible time-limit. The time expected to break down totally relies upon the material, natural conditions, for example, temperature and dampness, and area of decay as per Biodegradable Products Institute ${ }^{7}$.

The theory behind bio-plastics is quite clear and basic: on the off chance that we could make plastics from kinder synthetic concoctions to begin with, they would separate all the more rapidly and effectively when we dispose them off. The most recognizable bioplastics are produced using common materials, for example, corn starch and sold under such names as EverCorn ${ }^{\mathbf{T M}}$ and NatureWorks - with an impeccable accentuation on ecological qualifications. Some bio-plastics look for all intents and purposes undefined from conventional petrochemical plastics.

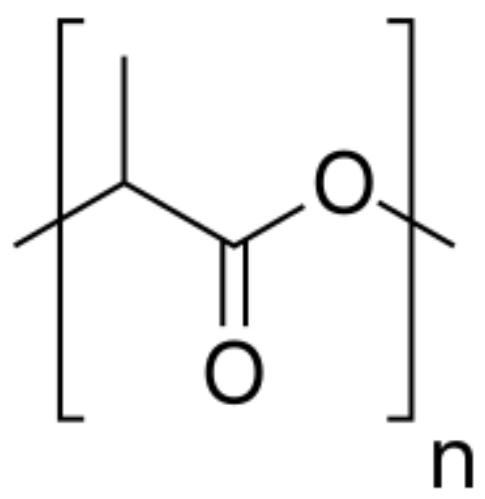

${ }^{6}$ By Team McCoy Mart distributors and manufacturers, August 17, 2017

${ }^{7}$ Biodegradable Products institute, 'Confused by the terms biodegradable and bio-based' 
- The above diagram representing the chemical formula of PLA's - $\left(\mathrm{C}_{3} \mathrm{H}_{4} \mathrm{O}_{2}\right)_{n}$ Polylactide acid (PLA) looks and behaves like polyethylene and polypropylene and is currently generally utilized for sustenance holders. As per NatureWorks, making PLA spares $66 \%$ the vitality you have to make customary plastics. In contrast to customary plastics and biodegradable plastics, bioplastics for the most part don't deliver a net increase in carbon dioxide gas when they separate (on the grounds that the plants that were utilized to make them ingested a similar measure of carbon dioxide in the first place). PLA, for instance, delivers right around 70 percent less ozone harming substances when it debases in landfills. ${ }^{8}$

4. Production of Paper pulp from groundnut shells -As of late, with the developing deficiency of wood from the backwoods, the quest for an alternative fibre creating plant material has been started in numerous nations of the world. The age of quickly developing high biomass yielding plant is believed to be one of the answers for meeting the deficiency of cellulosic material. In any case, certain horticultural plants creating higher biomass are observed to be reasonable substitute for certain fiber based businesses.

Among them groundnut shells may serve halfway as an alternative resource. They (Pulp) can be created from waste groundnut shells utilizing Kraft's procedure and Soda procedure, and furthermore dissect both the procedure depending on their yield and vitality utilization.

Groundnut naturally known as Arachishypogeae has a place to leguminous family. It is the fourth biggest oil seed discovered in world and India is the second biggest maker of groundnut after china. A total seed of groundnut is called as unit and external layer of groundnut is called shell. Pretty much all aspects of groundnut is of business esteem. Groundnut seeds are healthfully rich because of the nearness of oil, protein, minerals, nutrients and so on.

\begin{tabular}{|c|c|c|c|c|}
\hline Spacies & $\begin{array}{l}\text { Cellulose } \\
\text { (wit) }\end{array}$ & $\begin{array}{l}\text { Hemicellulose } \\
\text { (w\%) }\end{array}$ & $\begin{array}{l}\text { Ligin } \\
\text { (w\%) }\end{array}$ & $\begin{array}{l}\text { Ash } \\
\text { (wi\%) }\end{array}$ \\
\hline Pine (softwood) & $40-45$ & 25.30 & 26.34 & . \\
\hline Maple (thodwood) & 45.50 & 22.30 & $22: 30$ & . \\
\hline Bman & 63.64 & 19 & $s$ & . \\
\hline Cois & 3243 & $0.15-0.25$ & $40-45$ & . \\
\hline Sisal & 63.64 & 12 & $10-14$ & . \\
\hline Jute & 61.713 & 12.20 .4 & 118.13 & 2 \\
\hline Kená & $31 \cdot 39$ & 21.5 & 15.19 & . \\
\hline Hemp & 70.2 .744 & 17.9 .22 .4 & 3.7 .5 .7 & . \\
\hline Bagass: & $40-46$ & 24.5 .29 & 125.20 & 15.2 .4 \\
\hline Groundust shell & 33.7 & 18.7 & 30.2 & 3.9 \\
\hline Rice bosk & 313 & 243 & 143 & 235 \\
\hline Pineapple & 81 & . & 12.7 & . \\
\hline
\end{tabular}

${ }^{8}$ Chris Woodford 'Biopplastics and Bio-degradable plastics' April 30, 2019 
- The above data representing the Groundnut fibre shell properties.

There is flexibility as for the groundnut seed utilization, since it is expended in crude or cooked or salted or improved states in Indian nourishment arrangements. Groundnut is additionally of incentive as turn crop. As it is the plant that improves soil supplements, because of the nearness of climatic nitrogen fixing microscopic organisms in its root knobs while the dry plant parts are utilized as grain. In this way, all pieces of groundnut plant are completely helpful.

Groundnut shells have great potential for commercial use as well. As it is used as a fuel, filler in cattle feed, hard particleboard, cork substitute, activated carbon, etc., de-hulled groundnut husk is used in production of hard boards. The groundnut shell fibres possess good physical strength properties and the higher pentosan content together with gumsand mucilage in the sheath of certain species of groundnutplant may be a suitable source for producing paper. Although, reports are available on utilization of groundnut shell fibre for textile, pulp and paper making, but the market for creating groundnut shells through the Kraft and Soda process are quite limited.

In spite of the fact that Soda procedure requires just a single synthetic, yet in huge adds up to adequately breaking the lignin bonds. Kraft procedure requires fewer measures of various synthetic substances and likewise helps in complete lignin atom breakage. From this we can reason that Kraft procedure is increasingly favorable.

Now, regarding the heat prerequisite, the Kraft procedure is a more favorable position, in light of the fact that the cooking alcohol can break and break down the lignin in it. Soda procedure is provided with warmth for one hour more and still the cooking alcohol couldn't successfully process the lignin.

Paper mash obtained in the wake of washing is included with blanching operator. The measure of blanching operator required is more in the Soda procedure when contrasted with Kraft process. In this way, the paper mash obtained in Kraft procedure can be utilized for high evaluation paper generation. Mash acquired by Soda procedure can beutilized for poor quality paper creation.

\begin{tabular}{|c|l|c|c|}
\hline S.No & Process & $\begin{array}{c}\text { Groundnut } \\
\text { shells taken } \\
\text { (grams) }\end{array}$ & $\begin{array}{c}\text { Pulp Produced } \\
\text { (grams) }\end{array}$ \\
\hline 1 & Kraft's Process & 5 & 1.735 \\
\hline 2 & Soda Process & 5 & 1.273 \\
\hline
\end{tabular}

- The above data representing the relative amounts of paper pulp produced by both the procedures.

In any case, the issue being discussedhere is about the pressing paper. In this way, the mash must be completely lignin free, since it goes about as a polluting influence and may fluctuate the state of the pressed material. By this, we can reason that Kraft procedure is more secure.

At last, going to the yield from the perceptions, Kraft procedure gave more mash for 
fixed measure of crude material at the point when contrasted with Soda process. In this way, Kraft procedure is progressively beneficial.

The market for incentivizing Kraft procedure is even bigger. Sustaining such production levels and turning them to create newspapers, magazines and basically disposable reading materials which would require less intervention of virgin materials and would be sustained economically by giving it a brand image and the appropriate recognition. ${ }^{9}$

5. Clay utensils and Earthen kitchenware - In spite of the fact that the earthen pot has a long history in India, it is utilized for cooking in South Asia, a few pieces of South East Asia and furthermore in Africa. In India, it has likewise been concurred as religious sacredness.

In the sanctuary town of Puri in east India, the 'dal-chawal' (lentil and rice) made as an offering to the Gods, is arranged distinctly in earthen pots or handis. The clerics have a basic clarification: "The earth is unadulterated, and just unadulterated things can be offered to God." But this straightforward proclamation is stacked with logical thinking. It has been logically demonstrated that the remaining parts of a human body (as it returns to around 20 gms of residue) contain 18 miniaturized scale supplements including calcium, phosphorous, zinc, sulfur and iron. These are the extremely small scale supplements found in the dirt used to make mud pots. So when the ministers state, "Just unadulterated things can be offered to God", it is a splendidly judicious, even quite logical.

\section{Legislative Considerations}

The ardent purpose is to create waste management laws that administer the vehicle, treatment, stockpiling, and transfer of all way of waste, including metropolitan strong waste, hazardous waste, and nuclear waste, among numerous different sorts. Waste laws are commonly intended to limit or wipe out the uncontrolled dispersal of waste materials into the earth in a way that may cause environmental or natural mischief, and incorporate laws intended to lessen the age of waste and advance or command waste recycling. Administrative endeavours incorporate distinguishing and classifying waste sorts and ordering transport, treatment, stockpiling, and transfer rehearses.

Taking the given products into consideration, there needs to be an establishment of a treaty between the participating countries and states which would give a binding force to all the signatories regarding the importance of following and implementing such products in their economic spheres.

Waste Transfer guidelines are to be overseen as the passability, technique, and area of transfer of a specific waste. Such gauges might be intended to ensure human wellbeing and solace, and ecological qualities. Policy guidelines need to exist to control transfer.

Waste disposal might be confined completely by means of a transfer boycott. The most well-known and broad standard is a disallowance on littering. Where a ward has approved a particular spot or framework for garbage accumulation, statement or

9 IJSER Volume 7, issue 6 'A production of Paper pulp from groundnut shells' by Y N Ramgopal, M ReshmaChowdary and V Chaitanya 
deserting of rubbish somewhere else might be liable to common or criminal penalties. ${ }^{10}$ Other progressively explicit transfer bans - from commanding that paint not be poured down channels, to indicating national vaults for radioactive waste - all demonstration to oversee the last resting spot of different squanders. Still, different types of waste might be required to be isolated for reusing, as opposed to transfer. These disallowances are, it could be said, contingent, in that they don't by and large boycott the transfer of the material, but instead confine the transfer area.

Squander transfer additionally might be limited restrictively by necessitating that a waste be treated in a particular style before it might be discarded at a specific area. One such program is the United States Environmental Protection Agency's Land Disposal Restrictions under the Resource Conservation and Recovery Act Subtitle C unsafe waste administration program. These principles limit the land transfer (situation in landfills, principally) of risky waste without earlier affirmed projects. The "transfer restriction" commands that perilous waste can't be arranged ashore until it is blessed to receive and meet indicated qualities (adequate ignitability, destructiveness, reactivity, and toxicity), or is treated by determined endorsed treatment strategies. The "weakening forbiddance" banishes including a lot of water, soil, or non-risky waste so as to maintain a strategic distance from indicated treatment. The "capacity denial" enables waste to be put away just for the motivations behind gathering for treatment, as opposed to just put away inconclusively to dodge treatment. ${ }^{11}$

As stated earlier in my paper, the growing concerns regarding single-use plastic bags is imminent, and along with the accumulation of unwanted plastic which ultimately goes to landfill or incineration. The signatory states must implement and forge laws so that all the products be utilized and dispersed within their respective economies, and replace their adversaries.

Now, in an effort to consolidate such ideas, mere suggestions are not enough or completely helpful in bringing about the maximum potential of such products. There must be an insight upon the data collected by various waste management and collection agencies and a legislative draft must be prepared in order to tackle the stated issues, globally to locally -

1. An improved and a reconstructed landfill directive which shall govern all the signatories (Participating states) in order to scrutinize even further, the segregation of trash while being pummeled into the landfill. The exorbitant levels of toxicities that are involved with them are evident enough.

2. A formal draft upon which the above stated products be put in production and replace their adversaries, first being the polyester derived from plastics. This can work two-fold with proper collection and segregation of waste, and singling PET to rPET's, re-usable and recyclable plastic so as to maximize it's potential in the retail industry, funded by the state's treasuries at first, and after building a better brand image, to make the program self-sufficient enough to fund it's own circulation.

3. Second being the amendments of every signatory state to rescind and accept in it's

${ }^{10}$ See, e.g., NCSL, List of States with Littering Penalties.

11 U.S. EPA, http://www.epa.gov/osw/hazard/tsd/ldr/f99043.pdf Land Disposal Restrictions for Hazardous Wastes: A Snapshot of the Program]. 
individual common laws to use Fly ash bricks (FAB's) for sole construction purposes in terms of all types of complexes, housing, office spaces, stadiums, religious places, educative institutions, Hospitals, etc. And implement these strictly in accordance to the common house and town planning rules and regulations for any future construction purposes.

4. It is important to realize and acknowledge the roots and original intent of bringing about such a legislation. It is most definitely not to pander to profits or excess gains as that would lead to amassing the funds required for the waste collection programs as signed and accepted by the States. Even the mere profits derived from such an expansion into retail is to be then put back into waste collection programs.

5. The legislation would mandate strict rules of encumbering the funds derived from polyester-made garments to serve and sustain such waste collection programs. Proper segregation of waste, between un-usable and toxic leachate and re-usable plastic.

6. As a part and parcel of the legislation itself, it is to be directed that the state itself promotes such wear-ability and endorsement of a brand image which shall surround garments procured from recycled polyester. Any other non-recycled wear or any wear generated from virgin materials, must be heavily scrutinized and completely regulated on a need-basis. The conducive analogy being, that garments from non-recycled polyester are to be taxed and be removed of all subsidies to as to boost the funding program for establishing the market for waste collection programs and market establishment.

7. Heavy taxation upon the garments derived from virgin materials will indicate the seriousness, along with bridging any monetary considerations required to cover the costs in order to implement such a program. It shall bridge any other monetary gaps as well, such as labor costs, brand establishing costs, as well as, costs related to segregation of reusable and recyclable materials.

8. Now, in order to effectively combat the plastic overflow, a complete ban on single-use plastic bags must take place prior to the signing of the complete legislation by all the signatory states and participating nations. And a nominal exchange must take place in order to introduce bio-plastics and bio-degradable plastics. These single use bags and carrying apparatus are to be ensured of complete bio-degradation and what is to be charged to the civilians is, a nominal amount, a rather cost fee of the 'bio-plastic bag'. It is to also be ensured by the states to voluntarily distribute such bio-degradable bags to the lower-income sections of the society.

9. The next effort of the legislation being, to levy taxes to paper-producing corporations which are strictly derived from virgin materials (trees, natural habitat) and re-utilizing the similar funding to promote a digital society and a paper-less economy. The entailing theory is that monetarily, the taxing should be promoted within the legislation to such an extent and time-being so as to fully discourage paper-flow in the market and state completely. And since the digital revolution is already on it's course, promoting reading material, by legislation as well, to be derived from recycled paper as well so as to maximize the flow of recycled paper in the economy. Reading materials ranging from magazines, newspapers, pamphlets, brochures, posters, books, novels, notebooks, articles, circulated directories, etc.

10. The preliminary provisions within the legislations should also restrict and completely discourage landfilling and incineration of waste and to counter it, levying heavy penalties 
upon the state subjects that do not meet the prescribed landfilling standards, such as, limiting and prescribing the maximum amount of waste that can be subjected to landfills. 11. A more combative solution within the legislation is to charge and levy a heavy tax and penalty upon the corporation or the company of the waste that is found in the landfill (by way of sanctions). This will also discourage corporations from using plastic and non-biodegradable based materials. The Vicarious liability must be followed to the top of the pollution chain. Turning the polluter-pays principle into a reality, and not just a mere treaty.

\section{Conclusion}

Waste separation from the family level, appropriate capacity, increasingly productive waste gathering frameworks, and manageable recuperation and transfer practices are distinguished as required procedures in the investigation region. Considering the nature and parts of waste produced by family units and business puts, the waste decrease, reuse, reusing and fertilizing the soil procedures would be increasingly appropriate in dealing with the test.

These administration choices must be incorporated in a maintainable system, as quoted by the legislation. Satisfactory thought ought to be given to checking forms. State funded instruction and appropriately arranged waste administration programs likewise should be brought into the present waste administration framework. Particularly mindfulness projects must be directed so as to improve the learning about the significance of SWM for sound ecological advancement in the zone. The specialists ought to accommodate the presentation of the complimentary projects as mentioned earlier and approach improvement.

The ardent purpose being, to create a sustainable environment by way of equitable solutions and legislative enforcement so as to ensure a brighter future for the next of kin.

\section{References}

Environment Victoria, "sustainable living", 16 th June, 2013

Handbook of Solid Waste management' by Frank Kreith (eds)The McGraw-Hill Companies, Inc. 2002 under license agreement with Books $24 \times 7$

BIR Study on the Environmental Benefits of Recycling, 2018

OECD Policy brief, 2017

Fly ash for Sustainable Development authored by $\operatorname{Dr} \mathrm{N}$ Bhanumathidas and $\mathrm{N}$ Kalidas; Ark Communications 2002

Team McCoy Mart distributors and manufacturers, August 17, 2017

Biodegradable Products institute, 'Confused by the terms biodegradable and bio-based'

Chris Woodford 'Biopplastics and Bio-degradable plastics' April 30, 2019

IJSER Volume 7, issue 6 'A production of Paper pulp from groundnut shells' by Y N Ramgopal, M ReshmaChowdary and V Chaitanya

See, e.g., NCSL, List of States with Littering Penalties.

U.S. EPA, http://www.epa.gov/osw/hazard/tsd/ldr/f99043.pdf Land Disposal Restrictions for Hazardous Wastes: A Snapshot of the Program].

"United Nations Statistics Division - Environment Statistics". unstats.un.org. Retrieved 3 March 2017.

^ "Editorial Board/Aims \& Scope". Waste Management. 34 (3): IFC. March 2014. doi:10.1016/S0956053X(14)00026-9. 
^ "United Nations Statistics Division - Environment Statistics". unstats.un.org. Retrieved 3 March 2017.

^ Davidson, Gary (June 2011). "Waste Management Practices: Literature Review" (PDF). Dalhousie University Office of Sustainability. Retrieved 3 March 2017.

$\wedge$ "Glossary of environmental and waste management terms". Handbook of Solid Waste Management and Waste Minimization Technologies. Butterworth-Heinemann. 2003. pp. 337-465. doi:10.1016/B978-0750675079/50010-3. ISBN 9780750675079.

^ Albert, Raleigh (4 August 2011). "The Proper Care and Use of a Garbage Disposal". Disposal Mag. Retrieved 3 March 2017.

By Prabir Basu: Biomass Gasification, Pyrolysis and Torrefaction: Practical Design and Theory

^ Chen, Dezhen; Yin, Lijie; Wang, Huan; He, Pinjing (December 2014). "Pyrolysis technologies for municipal solid waste: A review". Waste Management. 